\title{
Framework for Promotion of Medical Tourism: A Case of India
}

\author{
Vinaytosh Mishra $^{1}$ (D) Mohita G. Sharma ${ }^{1}$ (i) \\ Received: 26 April 2021 / Accepted: 19 June 2021 / Published online: 28 June 2021 \\ (c) Global Institute of Flexible Systems Management 2021
}

\begin{abstract}
Medical tourism is quickly growing in developing countries. The healthcare players have recognized it as a potential area for economic diversification. The major factors affecting medical tourism in a country are cost, quality, language, and ease of travel. The healthcare services in India cost significantly lower than in western countries and the middle east. That is one of the reasons behind India attracting customers from these countries. The government promotes India as a premier healthcare destination and has made policies to ease travel for medical tourism purposes. Quality has been one of the important criteria for the selection of healthcare providers even for price-conscious customers. This study uses the case of the eastern part of the state of Uttar Pradesh to investigate the reason behind the low penetration of medical tourism in the region. The study identifies factors affecting medical tourism in post-COVID times and maps them with enablers using a focus group discussion. The study further uses SERVQUAL, a multidimensional research instrument to measure service quality by capturing patient's expectations and perceptions along five dimensions of service quality. The study contributes to the existing literature in two ways. It provides the framework for the promotion of medical tourism in a region. Second, it provides future directions for research in the area of medical tourism in the post-COVID world.
\end{abstract}

Keywords Service quality $\cdot$ SERVQUAL $\cdot$ Export competitiveness $\cdot$ Medical tourism

\section{Introduction}

Medical tourism (MT) has been growing enormously in the past few decades. This has been especially favorable for many developing countries especially in Asia wherein there is travel between upper-income countries and lower- and middle-income countries for healthcare purposes (Behrmann \& Smith, 2010). The drivers for this travel have been prohibitively expensive, inadequate, or unavailable in their high-income home countries and the services could include cosmetic, wellness, and dental treatments, and has been collectively called medical tourism (Connell, 2006; Turner, 2011). Especially governments and private-sector actors in Asia, Europe, and Latin America have begun to actively promote their countries, cities, and medical facilities as medical tourism destinations to boost and diversify their tourism and

Vinaytosh Mishra

vinaytosh@fsm.ac.in

Mohita G. Sharma

mohita@fsm.ac.in

1 QT and OM Area, FORE School of Management, New Delhi, India healthcare offerings (Wong \& Musa, 2012). Various governments have also promoted their country as a medical tourism destination through policy interventions. In a recent study, the economic performance of medical tourism is analyzed vis-a-vis overall community satisfaction, health care satisfaction, and attitudes toward medical tourism through a combination of social exchange theory with spillover theory. This is shown in a study where for a particular region the residents' perceptions of medical tourism's impact on community wellbeing also affect willingness to pay higher taxes and support for medical tourism development (Suess et al., 2018).

If we focus on India, the main driver of the growth of medical tourism has been the highly trained medical fraternity who is adept in English (Crooks et al., 2011). India has over the years become the hub of medical tourism which is the confluence of the twin sectors of the tourism industry and health industry (Shanker, 2019). This falls under the category of service exports and has been instrumental in earning foreign exchange and huge employment opportunities for the country. Given the fact that the main objective of medical tourists is getting good quality medical treatment at a reasonable cost, the outward focus has to be on 
competitiveness and the inward focus has to be operational excellence to drive the cost down. In a previous study, Thailand, Singapore and India have been identified as the main players in medical tourism capturing $80 \%$ of Asia's medical tourism market (Mary, 2014). A comprehensive definition of medical tourism competitiveness has been given by Ganguli and Ebrahim, (2017) which can be stated as: "the ability to strategically plan, set viable policy goals, establish effective multi-stakeholder partnerships, maintain an attractive environment; and ensure that all of these capabilities are harmonized to optimize the delivery of medical services that rank high on parameters of quality, innovativeness, affordability, and safety".

The further reasons which make India an attractive medical tourism destination are ensuing (Bagga et al., 2020; Bies \& Zacharia, 2007; de Arellano, 2007).

- Demand: Emanating from the long waiting lists in the developed countries has resulted in patients moving to other healthcare destinations.

- Affordability and cost: The low cost of medical treatments in India makes it an enticing healthcare destination. In India, costs for complicated surgical procedures are almost one-tenth of the cost as compared to the procedures in the developed countries.

- Accessibility: Affordable and access to air routes from every part of the globe make India one of the favored medical tourism destinations. The country has a further favorable exchange rate which makes it an economically viable alternative. The government has even eased the visa rules for tourists visiting the country for medical tourism purposes.

- Communication: Indian healthcare workforce is good at English communication. The advancement in telemedicine helps patients in getting follow-up care, rehabilitative care after major surgery. This even eliminates the need for a follow-up visit to the country.

India attracts patients in areas namely wellness tourism, alternative systems of medicine, cosmetic surgery, and advanced and lifesaving healthcare. Thus, the Medical
Tourism structure can be broadly classified into the following four categories (Fig. 1).

Medical tourism is not a simple process. It is a complex decision by an international traveler based on the attributes of the host country, facilities of healthcare professionals, reasonable cost, and the service quality of hospitality and tourism (Chuang et al., 2014; Fetscherin \& Stephano, 2016; Olya \& Nia, 2021). Some studies are exploring the development of the Medical Tourism Index (MTI) and four dimensions of MTI include country environment, tourism destination, medical tourism costs, and medical facility and services (Fetscherin \& Stephano, 2016). In a detailed literature review and co-word citation analysis, Hoz-Correa et al. (2018) suggests that six themes dominate the research: (a) issues regarding ethical implications, trust, and accreditation; (b) health, wellness, spa tourism, and service quality; (c) health-related issues, medical treatments, and tourism; (d) "sensitive" practices in MT; (e) medical tourism destinations and marketing; and (f) globalization, policies and the effect on international patients.

Further, Ebrahim and Ganguli (2019) and Belladi et al. (2019) have done a strategic cross-country comparison and have elucidated that the extent of coordination among public and private MT stakeholders and a collaborative; administration efficiency of sectors such as medical, tourism, and economic sectors along with the development of medicine and related human capital contribute to enhancing the growth of the sector. In another cross-country study, exploring the hospital's website across five dimensions: hospital information and facilities, admission and medical services, interactive online services, external activities, and technical items, it was observed that there were differences between Indian, Malaysian, and Thai hospital websites and suggesting that there was a need for hospital managers to improve their hospitals' online presence and interactivity (Moghavvemi et al., 2017).

Cham et al. (2021) in their study of Chinese medical tourists to Malaysia have analyzed country-specific factors (country knowledge, safety and security, accessibility, and price reasonableness) and social factors (wordof-mouth and social media) to be significant predictors of

Fig. 1 Medical tourism structure in India

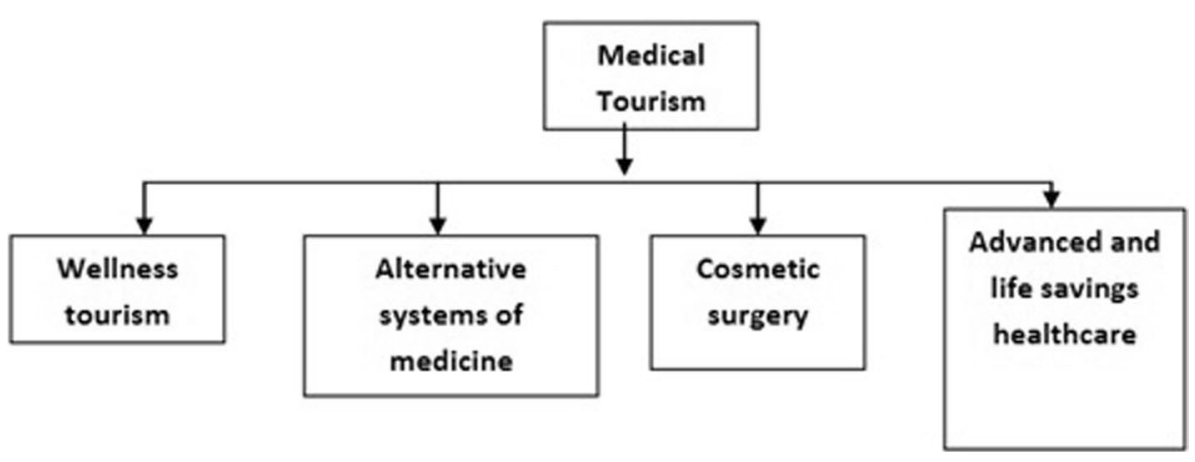


the image of Malaysia as a medical tourism destination, which in turn, affect the perceived value and intention to revisit. Another study provides an extended diamondbased pyramid framework of regional competitiveness and can be adopted for the medical tourism sector in a country (Moirangthem \& Nag, 2020). Ghosh and Mandal (2019) have cited in a study on India that treatment quality, medical service quality, medical tourism expenses, medical tourism infrastructure, destination appeal, destination culture, and ease of access increase the satisfaction and loyalty of medical tourists. Taking a stream from HozCorrea et al. (2018) of service quality, this study extends this inquiry into understanding the service quality dimensions for medical tourism, especially for India. The study highlights the importance of service quality in achieving operational excellence. The image of India is discolored due to the below-par performance of the health system during the COVID-19 pandemic and may impact the export competitiveness of medical tourism. It is imperative to assess the quality gap and take corrective measures to remain competitive.

The next section lists the objectives of this research followed by the methodology used in this study. Subsequent sections discuss the result and hence the conclusion for the study. In last but not least, the study lists the limitations of the research and the future agenda for the research.

\section{Research Objectives}

The objective of this research is threefold: (1) to use the extant literature to identify the factors affecting medical tourism, (2) to provide the framework for the development of medical tourism in a region using focus group discussion, and (3) to use the case of eastern Uttar Pradesh to analyze the service quality gap using established instrument SERVQUAL.

\section{Methodology}

The research reviews the extant literature to identify the factors affecting medical tourism in a region. The findings of the reviewed literature are listed in the introduction section of this paper. The first step included using the finding of the literature review and input from the focus group to propose a framework for the development of medical tourism in a region. The study in the second stage uses the SERVQUAL method to evaluate the case region on five dimensions of the service quality.

Services being distinguished by intangibility and consumed simultaneously, the quality of service is understood as the perception of value delivered (Lam et al., 2012). Nitecki and Hernon (2000) defined service quality in terms of "meeting or exceeding customer expectations, or as the difference between customer perception and expectations of service" (Wang \& Shieh, 2006). SERVQUAL is a multidimensional research instrument designed to measure service quality by capturing respondents' expectations and perceptions (Parasuraman et al., 2002). The instrument has been widely used to assess the quality of services in the industry such as retail, hospitality, and healthcare (Ajam et al., 2014; Saleh \& Ryan, 1991; Zhao et al., 2002). Thus for quantitatively assessing it, it is taken as the difference between the customer's perception of the service and his expectations in his mind. Perception is the comparison between expectations and actual performance. A positive indication of quality is when the performance is higher than expectations and vice versa.

Healthcare is a high involvement service with long-term engagement between the patient and service provider and SERVQUAL has been used to prioritize the dimensions and identify the gaps to be filled to enhance the competitiveness of the delivery process (Al-Neyadi et al., 2018; Traipathi \& Siddiqui, 2018). The SERVQUAL model has five dimensions of service quality namely reliability, assurance, tangibles, empathy, and responsiveness (Fig. 2).
Fig. 2 SERVQUAL model for service quality

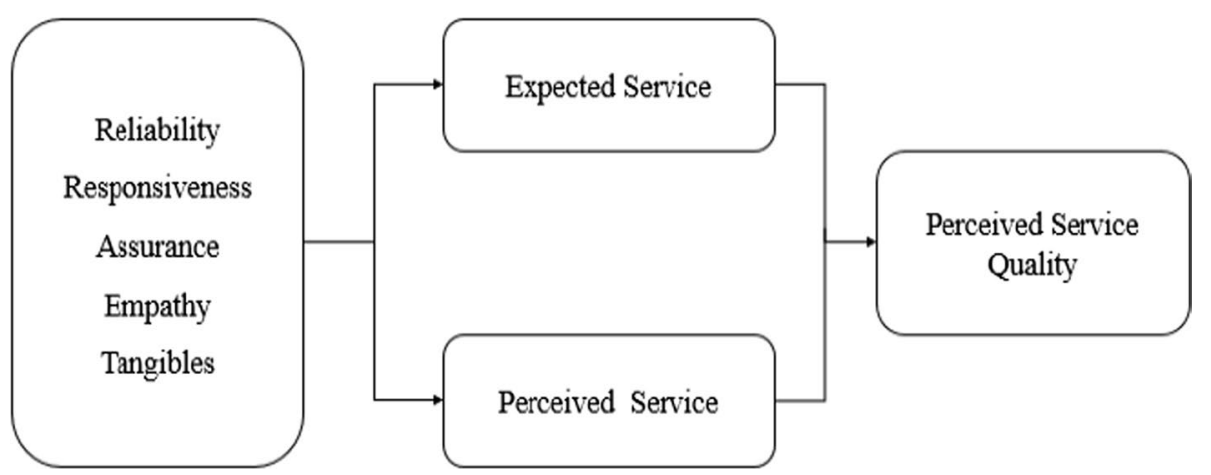


Table 1 Five dimensions of service quality

\begin{tabular}{ll}
\hline Dimension & Definition \\
\hline Reliability & The ability to perform the promised service dependably and accurately \\
Assurance & The knowledge and courtesy of employees and their ability to convey trust and confidence \\
Tangibles & The appearance of physical facilities, equipment, personnel, and communication materials \\
Empathy & The provision of caring, individualized attention to customer \\
Responsiveness & The willingness to help customers and to provide prompt service \\
\hline
\end{tabular}

The description of the five dimensions of service quality is listed in Table 1 (Butt et al., 2010; Parasuraman et al., 1988).

The researchers have used the established and timetested SERVQUAL for assessing the service quality in the case of medical tourism (Chou et al., 2012; Guiry \& Vequist, 2011; Qolipour et al., 2018).

The focus group used for objective one of the study is the healthcare professionals working in India. The size of the focus group is eight including the researchers as coordinators and passive members. A focus group larger than eight is difficult to manage (Fern, 1982). The focus group constituted four healthcare professionals, three doctors, and one healthcare researcher. Focus group discussion is frequently used as a qualitative approach to gain an indepth understanding of the problem at hand (Nyumba et al. 2018). This method uses data from a purposely selected group of individuals rather than from a statistically representative sample of a broader population. Even though the application of this method in management research has been extensive, there are no critical assessments of the application of the technique. In addition, there are no readily available guidelines for researchers. This study uses the Delphi method to gain consensus on the framework. The Delphi method is well suited as a research instrument when there is incomplete knowledge about a problem or phenomenon (Skulmoski, 2007). The approach adopted for the Delhi Method is depicted in Fig. 3 (Cooper, 2019).

The sample size for this exploratory study was taken as 31 and the sampling method was used as purposive sampling. The extant literature suggests that with purposive sampling a sample size of 30 for the exploratory study is adequate (Kowalska \& Ostręga, 2020). The questionnaire was sent to 50 prospects out of which 31 responded, making the response rate $62 \%$. The characteristics of the respondent are listed in Table 2.

To summarize, the study first identifies the factors and enablers for medical tourism in the region then uses the focus group's input to map it. The study then uses SERVQUAL for finding the quality gap. The summary of the research methodology used in the study is depicted in Fig. 4.

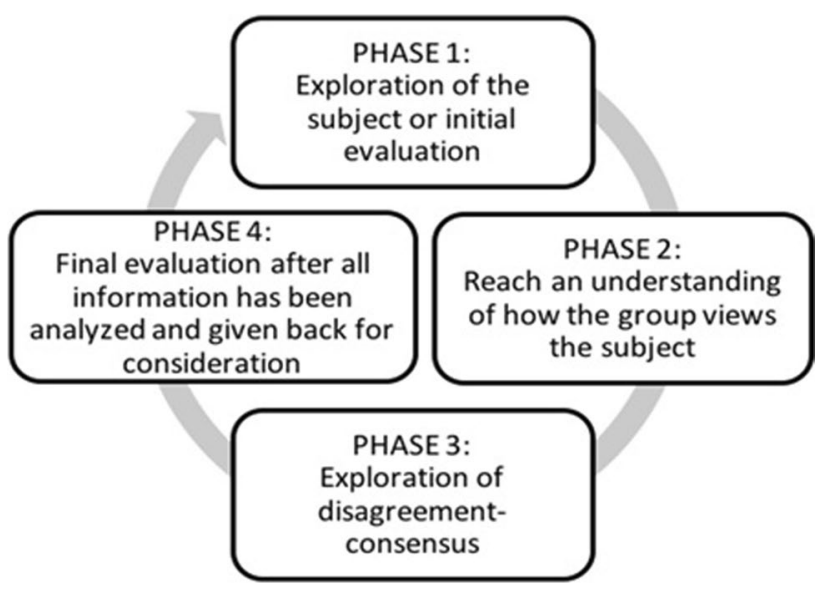

Fig. 3 Delphi approach for focus group

Table 2 Characteristics of respondents

\begin{tabular}{lcl}
\hline Description & Respondents & Percentage $(\%)$ \\
\hline Age & & \\
$<45$ & 6 & 19.35 \\
$45-55$ & 18 & 58.06 \\
$>55$ & 7 & 22.58 \\
Gender & & \\
Male & 18 & 58.06 \\
Female & 13 & 41.93 \\
Country & & \\
Mauritius & 4 & 12.90 \\
USA & 5 & 16.13 \\
UAE & 4 & 12.90 \\
India (other than eastern & 18 & 58.06 \\
$\quad$ UP) & & \\
\hline
\end{tabular}

\section{Results and Discussion}

Based on the research, the study identifies four major factors affecting the penetration of medical tourism in the region. The focus group discussion helped us in identifying cost, quality, language, and ease of travel as the four most important factors affecting the penetration of 
Fig. 4 Schematic diagram for the study

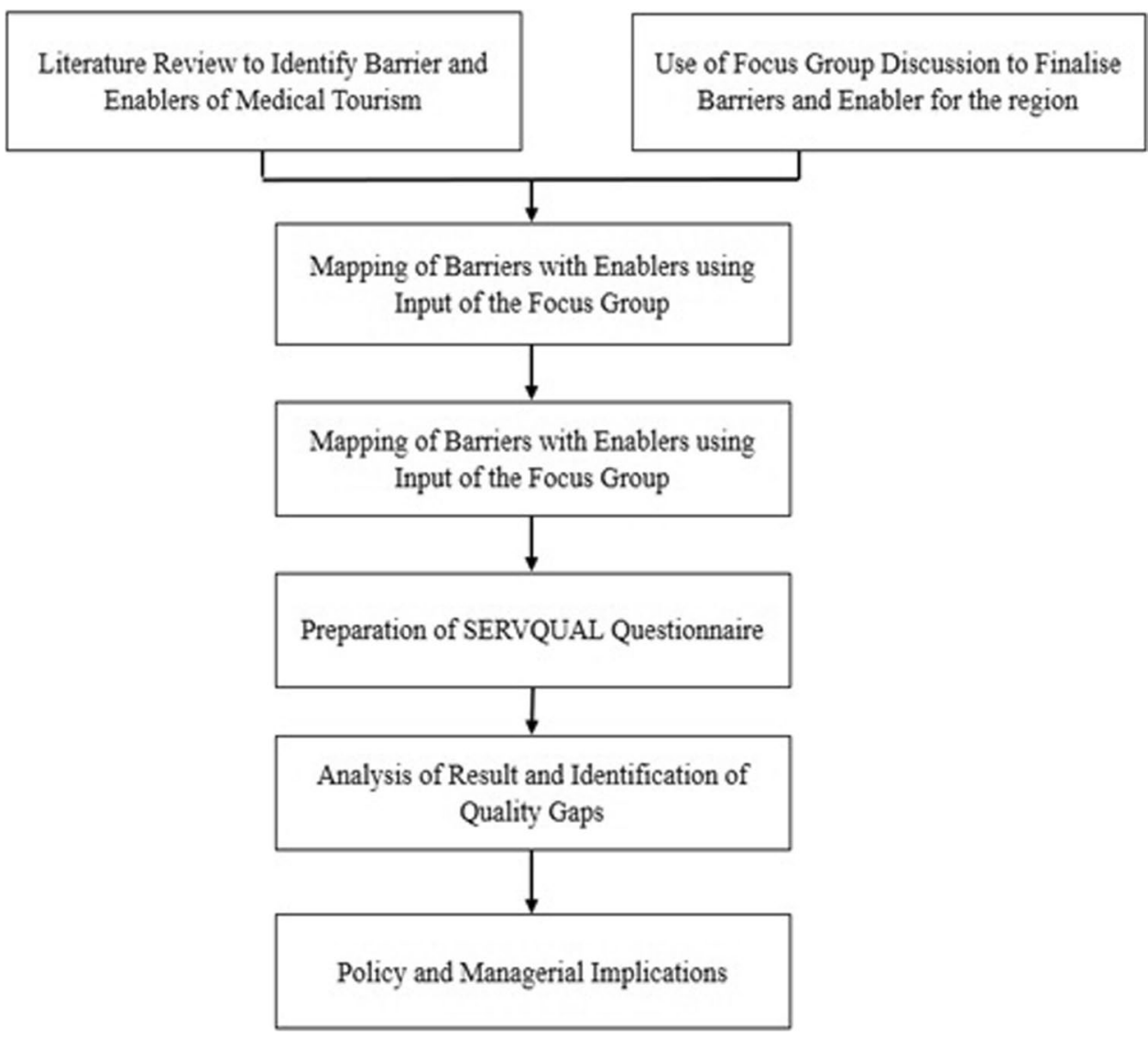

medical tourism in a region. The study further interviewed the focus group members to identify enablers for these identified factors. Based on the input of the focus group, the study proposes a framework for increasing the penetration of medical tourism in the case region. The secondary research and focus group discussion suggested lean management, use of quality management systems, having National Accreditation Board for Hospitals and Healthcare Providers (NABH) and External Quality Assurance
Systems (EQAS), language and soft skills, and ease of travel and visa rules as some of the important enablers for achieving the four factors. Figure 5 summarizes the framework using enablers and factors to increase the medical tourism in the region.

It can be seen that ease of Travel and Language are environmental factors and external to the control of business whereas Cost and Quality are within the control of the business. Cost and Quality are interlinked and emphasis on

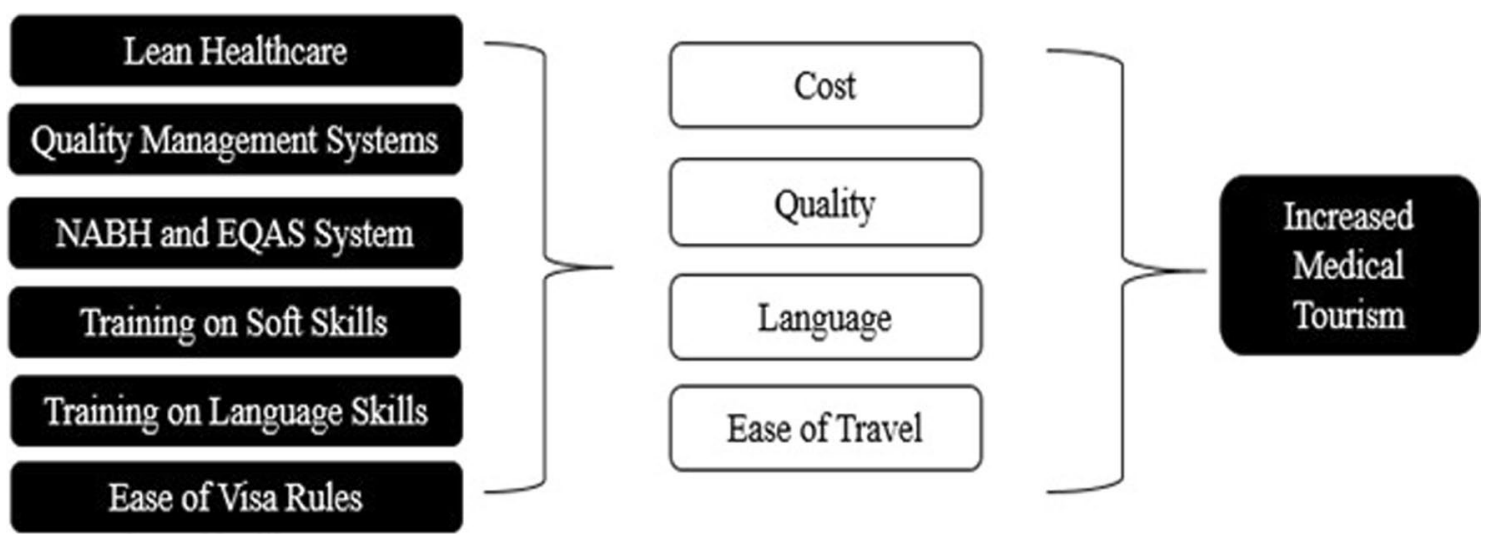

Fig. 5 Framework for increasing medical tourism 
Table 3 Summary of scores from SERVQUAL model

\begin{tabular}{llll}
\hline & Perception $(P)$ & $\begin{array}{l}\text { Expectation } \\
(E)\end{array}$ & $(P-E)$ \\
\hline Reliability & 5.53 & 9 & 3.47 \\
Responsiveness & 5.65 & 8 & 2.35 \\
Assurance & 6.1 & 9 & 2.9 \\
Empathy & 6.54 & 8 & 1.46 \\
Tangible & 6.03 & 7 & 0.97 \\
\hline
\end{tabular}

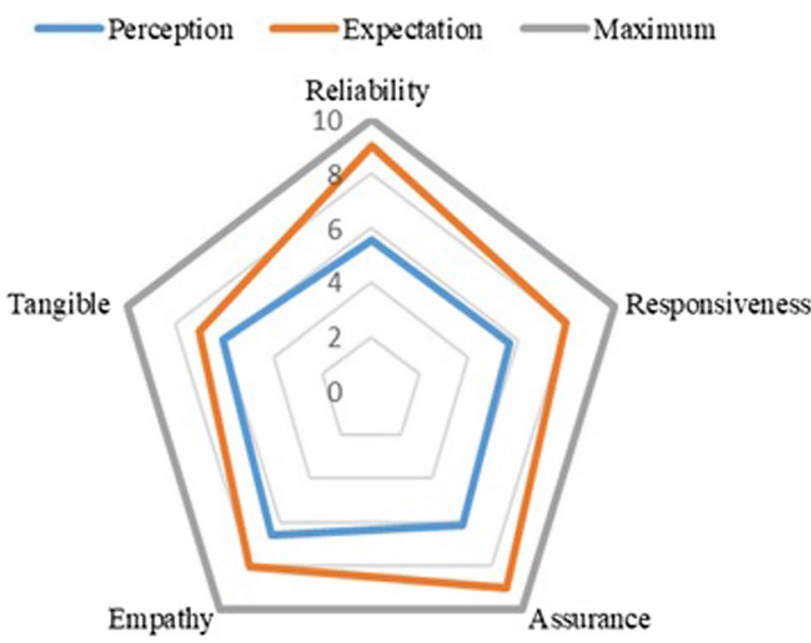

Fig. 6 Perception and expectation of service quality

quality can reduce the cost of operations thereby achieving operational excellence. Further, as the extant literature and focus group, discussion suggested quality is one of the most important criteria for the selection of a healthcare destination. The study adopted the SERVQUAL model which is a recognized tool to understand the difference between expectations and the perception of the service quality on five dimensions' reliability, responsiveness, assurance, empathy, and tangibles. The respondents were asked to give responses to 22 questions on a Likert scale of ten and the average of the score on the subdimensions was taken as a score for a dimension. Thus, the maximum possible score for any dimension is ten. The perception score $(P)$ and expectation score $(E)$ for the service quality is listed in Table 3 . The difference of $P$ and $E$ gives the gap between expectation and perception, the difference needs to be minimized to increase customer satisfaction (Gounaris et al., 2007).

Figure 6 depicts the perception, expectation of maximum value on five dimensions of the service quality. As the figure suggests the largest service gap is for reliability, followed by responsiveness and assurance. The minimum service gap is for the service dimension tangible but there is still a scope of improvement when we compare it with the maximum score possible.
The study also shows that maximum expectation is for dimension reliability, assurance followed by responsiveness and empathy. The gap between expectations and performance is large for Reliability and Assurance Dimensions. The reliability of the service can be enhanced by making the service more process-driven and adhering to management systems. The lesser the non-conformity is, the better the reliability. On the other hand, for 'assurance' the focus has to be on providing soft skill training to the personnel and attitude of service in the nurses and paramedical staff. It also depends on the work culture of the organization. The responsiveness of the service is 'how quickly the problem gets resolved. For addressing this parameter, the capacity of the supporting staff has to be enhanced so that the time of response gets reduced. It is observed that the tangibles and empathy gap is less which is a good sign. The customers are satisfied with the infrastructure and feel that they are understood. Given the fact that the empathy gap is less and the assurance gap is high, an attempt to enhance communication can reduce the assurance gap also.

\section{Conclusion}

The increased cost of care in western countries and the middle east has forced patients to look towards the east. Medical tourism is quickly growing in developing countries like India. Recent process innovation and operational excellence in India make it possible to deliver healthcare at a fraction of the cost compared to the western countries. The average cost of open-heart surgery, as reported by Narayana Health, is less than \$2000. The same procedure at a US research hospital typically costs more than $\$ 100,000$. The factors making a destination a preferred medical tourism destination is cost, quality, language, and ease of travel. The extant literature suggests that quality is one of the most important criteria for the selection of a healthcare provider (Mishra et al., 2019). A website listing the healthcare tourism destination in India lists only a few healthcare providers from eastern Uttar Pradesh. With the availability of vaccines and mass vaccination in many countries, borders have started opening again. The governments should think about measured to promote medical tourism in post-COVID times. This compelled us to investigate the reason behind the low penetration of medical tourism in the region and what can be done.

Studies have used the SERVQUAL method for quality assessment of private healthcare providers (Butt et al., 2010; Pekkaya, 2019). There is evidence of recent use of the SERVQUAL method for quality assessment in healthcare in developing countries (AlOmari, 2020; Tripathi \& Siddiqui, 2018). Qolipour et al. (2018) analyze the patient's perspective on the quality of medical tourism in Iran. Although there are studies on the evaluation of service quality of 
medical tourism destinations, there is a lack of studies done on quality assessment of medical tourism as eastern India as the destination, and this study attempts to fill this gap. This study uses a mix of qualitative and quantitative approaches for the development of a framework for promoting medical tourism in the region. The study further uses the SERVQUAL model to find out the patient's perception and expectation of healthcare services on five dimensions of service quality and identifies the area of improvement. The approach used in the study is simple and easy to follow and does not overwhelm a reader with excessive details. The study uses Radar Chart to visualize the quality gap related to five dimensions. The study will help healthcare providers and policymakers devise strategies for promoting medical tourism in a region. The finding of the study is also useful for healthcare administration to improve service quality in their organization to eventually attract patients from Gulf and Western Countries.

\section{Limitations and Future Directions}

The limitations of the study emanate from the model that has been adopted. Despite its strengths and widespread acceptance, SERVQUAL is sometimes disapproved of for its bounded lens and these criticisms are true for this study as well. The focus of the model is from an operations perspective, and so it fails to draw on established economic, statistical and psychological theory. The prime focus remains on service operations and delivery rather than the outcome. Some studies also reflect that the five dimensions of service quality used in the SERVQUAL are not universal (Buttle, 1996).

This study is exploratory and uses purposive sampling. A study having a larger sample size and probabilistic sampling will help generalize the finding to a larger population. The study can include samples from countries other than Mauritius, UAE and the US will make the study more inclusive. The majority of the respondents represent prospects from the age group 45-55. This may be one of the limitations of the study. A future study can empirically test the framework proposed in the study for the promotion of medical tourism in a region. Future studies can also include more service dimensions related to healthcare.

\section{Key questions reflecting applicability in real life}

1. What are factors affecting the penetration of medical tourism in a geographical region?
2. What are the enablers for these factors to attract medical tourists to the region?

3. What are the healthcare quality dimensions used in existing literature for medical tourism?

4. How to use the SERVQUAL method to identify and fill the service quality gaps?

Acknowledgements The infrastructural support provided by the FORE School of Management, New Delhi is greatly appreciated. The authors are also thankful to the editor and reviewer for their valuable input and comments, which have helped in improving the manuscript significantly.

Author Contributions VM: study planning, data collection and data analysis, and manuscript writing. MoGS: study planning, literature review, and manuscript writing.

Funding There is not any funding to report.

Availability of Data and Material Available on request.

Code Availability Not applicable.

\section{Declarations}

Conflict of Interest There is not any conflict of interest to report.

\section{References}

Ajam, M., Sadeghifar, J., Anjomshoa, M., Mahmoudi, S., Honarvar, H., \& Mousavi, S. M. (2014). Assessing the quality of healthcare service by the SERVQUAL model: A case study of a field hospital. Journal of Military Medicine, 15(4), 273-279.

Al-Neyadi, H. S., Abdallah, S., \& Malik, M. (2018). Measuring patient's satisfaction of healthcare services in the UAE hospitals: Using SERVQUAL. International Journal of Healthcare Management, 11(2), 96-105. https://doi.org/10.1080/20479700.2016. 1266804

AlOmari, F. (2020). Measuring gaps in healthcare quality using SERVQUAL model: Challenges and opportunities in developing countries. Measuring Business Excellence. https://doi.org/10.1108/ MBE-11-2019-0104

Bagga, T., Vishnoi, S. K., Jain, S., \& Sharma, R. (2020). Medical tourism: Treatment, therapy and tourism. International Journal of Scientific and Technology Research, 9(3), 4447-4453.

Behrmann, J., \& Smith, E. (2010). Top 7 issues in medical tourism: Challenges, knowledge gaps, and future directions for research and policy development. Global Journal of Health Science, 2(2), 80.

Beladi, H., Chao, C. C., Ee, M. S., \& Hollas, D. (2019). Does medical tourism promote economic growth? A cross-country analysis. Journal of Travel Research, 58(1), 121-135. https://doi.org/10. $1177 / 0047287517735909$

Bies, W., \& Zacharia, L. (2007). Medical tourism: Outsourcing surgery. Mathematical and Computer Modelling, 46(7-8), 1144-1159. https://doi.org/10.1016/j.mcm.2007.03.027

Butt, M. M., \& de Run, E. C. (2010). Private healthcare quality: Applying a SERVQUAL model. International Journal of Health Care 
Quality Assurance, 23(7), 658-673. https://doi.org/10.1108/09526 861011071580

Buttle, F. (1996). SERVQUAL: Review, critique, research agenda. European Journal of Marketing, 30(1), 8-32. https://doi.org/10. 1108/03090569610105762

Cham, T. H., Lim, Y. M., Sia, B. C., Cheah, J. H., \& Ting, H. (2021). Medical tourism destination image and its relationship with the intention to revisit: A study of Chinese medical tourists in Malaysia. Journal of China Tourism Research, 17(2), 163-191. https:// doi.org/10.1080/19388160.2020.1734514

Chou, S. Y., Kiser, A. I., \& Rodriguez, E. L. (2012). An expectation confirmation perspective of medical tourism. Journal of Service Science Research, 4(2), 299-318. https://doi.org/10.1007/ s12927-012-0012-3

Chuang, T. C., Liu, J. S., Lu, L. Y., \& Lee, Y. (2014). The main paths of medical tourism: From transplantation to beautification. Tourism Management, 45, 49-58. https://doi.org/10.1016/j.tourman. 2014.03.016

Connell, J. (2006). Medical tourism: Sea, sun, sand, and... surgery. Tourism Management, 27(6), 1093-1100. https://doi.org/10. 1016/j.tourman.2005.11.005

Cooper, C. (2019). Critical competencies needed for outside sales managers: A Delphi study. SAGE Publications Ltd.

Crooks, V. A., Turner, L., Snyder, J., Johnston, R., \& Kingsbury, P. (2011). Promoting medical tourism to India: Messages, images, and the marketing of international patient travel. Social Science \& Medicine, 72(5), 726-732

Crooks, V. A., Turner, L., Snyder, J., Johnston, R., \& Kingsbury, P. (2011). Promoting medical tourism to India: Messages, images, and the marketing of international patient travel. Social Science \& Medicine, 72(5), 726-732.

De la Hoz-Correa, A., Muñoz-Leiva, F., \& Bakucz, M. (2018). Past themes and future trends in medical tourism research: A co-word analysis. Tourism Management, 65, 200-211. https://doi.org/10. 1016/j.tourman.2017.10.001

De Arellano, A. B. R. (2007). Patients without borders: The emergence of medical tourism. International Journal of Health Services, 37(1), 193-198. https://doi.org/10.2190/4857-468G-2325-47UU

Ebrahim, A. H., \& Ganguli, S. (2019). A comparative analysis of medical tourism competitiveness of India, Thailand, and Singapore. Tourism an International Interdisciplinary Journal, 67(2), 102-115.

Fern, E. F. (1982). The use of focus groups for idea generation: The effects of group size, acquaintanceship, and moderator on response quantity and quality. Journal of Marketing Research, 19(1), 1-13. https://doi.org/10.1177/002224378201900101

Fetscherin, M., \& Stephano, R. M. (2016). The medical tourism index: Scale development and validation. Tourism Management, 52, 539-556. https://doi.org/10.1016/j.tourman.2015.08.010

Ganguli, S., \& Ebrahim, A. H. (2017). A qualitative analysis of Singapore's medical tourism competitiveness. Tourism Management Perspectives, 21, 74-84. https://doi.org/10.1016/j.tmp.2016.12. 002

Ghosh, T., \& Mandal, S. (2019). Medical tourism experience: Conceptualization, scale development, and validation. Journal of Travel Research, 58(8), 1288-1301. https://doi.org/10.1177/0047287518 813469

Gounaris, S. P., Tzempelikos, N. A., \& Chatzipanagiotou, K. (2007). The relationships of customer-perceived value, satisfaction, loyalty, and behavioral intentions. Journal of Relationship Marketing, 6(1), 63-87. https://doi.org/10.1300/J366v06n01_05

Guiry, M., \& Vequist, D. G. (2011). Traveling abroad for medical care: US medical tourists' expectations and perceptions of service quality. Health Marketing Quarterly, 28(3), 253-269. https://doi.org/ $10.1080 / 07359683.2011 .595644$
Kowalska, N., \& Ostręga, A. (2020). Using SERVQUAL method to assess tourist service quality by the example of the Silesian Museum Established on the post-mining area. Land, 9(9), 333. https://doi.org/10.3390/land9090333

Lam, S., Lee, V., Ooi, K., \& Phusavat, K. (2012). A structural equation model of TQM, market orientation and service quality: evidence from a developing nation. Managing Service Quality, 22(3), 281309. https://doi.org/10.1108/09604521211230996

Mary, S. S. (2014). Medical tourism in Asia-an overview. Scholars World-IRMJCR, 2, 131-136.

Mishra, V., Samuel, C., \& Sharma, S. K. (2019). Patient's utility for various attributes of diabetes care services. IIM Kozhikode Society and Management Review, 8(1), 1-9. https://doi.org/10.1177/ 2277975218798134

Moghavvemi, S., Ormond, M., Musa, G., Isa, C. R. M., Thirumoorthi, T., Mustapha, M. Z. B., \& Chandy, J. J. C. (2017). Connecting with prospective medical tourists online: A cross-sectional analysis of private hospital websites promoting medical tourism in India, Malaysia, and Thailand. Tourism Management, 58, 154-163. https://doi.org/10.1016/j.tourman.2016.10.010

Moirangthem, N. S., \& Nag, B. (2020). Developing a framework of regional competitiveness using macro and microeconomic factors and evaluating sources of change in regional competitiveness in India using Malmquist Productivity Index. International Journal of Global Business and Competitiveness, 15(2), 61-79. https://doi.org/10.1007/s42943-020-00016-2

Nitecki, D. A., \& Hernon, P. (2000). Measuring service quality at Yale university's libraries. Journal of Academic Librarianship, 26(4), 259-273. https://doi.org/10.1016/S0099-1333(00) 00117-8

Nyumba, T. O., Wilson, K., Derrick, C. J., \& Mukherjee, N. (2018). The use of focus group discussion methodology: Insights from two decades of application in conservation. Methods in Ecology and Evolution, 9(1), 20-32. https://doi.org/10.1111/2041-210X. 12860

Olya, H., \& Nia, T. H. (2021). The medical tourism index and behavioral responses of medical travelers: A mixed-method study. Journal of Travel Research, 60(4), 779-798. https://doi.org/10. $1177 / 0047287520915278$

Parasuraman, A., Zeithaml, V. A., \& Berry, L. (1988). SERVQUAL: A multiple-item scale for measuring consumer perceptions of service quality. Journal of Retailing, 64(1), 12-40.

Parasuraman, A., Berry, L., \& Zeithaml, V. (2002). Refinement and reassessment of the SERVQUAL scale. Journal of Retailing, 67(4), 114-139.

Pekkaya, M., Pulat İmamoğlu, Ö., \& Koca, H. (2019). Evaluation of healthcare service quality via SERVQUAL scale: An application on a hospital. International Journal of Healthcare Management, 12(4), 340-347. https://doi.org/10.1080/20479700.2017. 1389474

Qolipour, M., Torabipour, A., Khiavi, F. F., \& Malehi, A. S. (2018). Assessing medical tourism services quality using SERVQUAL model: A patient's perspective. Iranian Journal of Public Health, 47(1), 103-110

Saleh, F., \& Ryan, C. (1991). Analyzing service quality in the hospitality industry using the SERVQUAL model. Service Industries Journal, 11(3), 324-345. https://doi.org/10.1080/0264206910 0000049

Sankar, P. (2019). Medical tourism in India: Issues, opportunities and designing strategies for growth and development. Sociology of Medical Tourism, (pp. 227-240). Chennai: MJP Publishers

Skulmoski, G. J., Hartman, F. T., \& Krahn, J. (2007). The Delphi method for graduate research. Journal of Information Technology Education Research, 6(1), 1-21.

Suess, C., Baloglu, S., \& Busser, J. A. (2018). Perceived impacts of medical tourism development on community wellbeing. Tourism 
Management, 69, 232-245. https://doi.org/10.1016/j.tourman. 2018.06.006

Tripathi, S. N., \& Siddiqui, M. H. (2018). Assessing the quality of healthcare services: A SERVQUAL approach. International Journal of Healthcare Management. https://doi.org/10.1080/20479 700.2018.1469212

Turner, L. G. (2011). Quality in health care and globalization of health services: Accreditation and regulatory oversight of medical tourism companies. International Journal for Quality in Health Care, 23(1), 1-7. https://doi.org/10.1093/intqhe/mzq078

Wang, I., \& Shieh, C. (2006). The relationship between service quality and customer satisfaction: The example of CJCU library. Journal of Information Optimization Services, 27(1), 193-209. https://doi. org/10.1080/02522667.2006.10699686

Wong, K. M., \& Musa, G. (2012). Medical tourism in Asia: Thailand, Singapore, Malaysia, and India. Medical tourism: The ethics, regulation, and marketing of health mobility. Routledge.

Zhao, X., Bai, C., \& Hui, Y. V. (2002). An empirical assessment and application of SERVQUAL in a mainland Chinese department store. Total Quality Management, 13(2), 241-254. https://doi.org/ 10.1080/09544120120102478

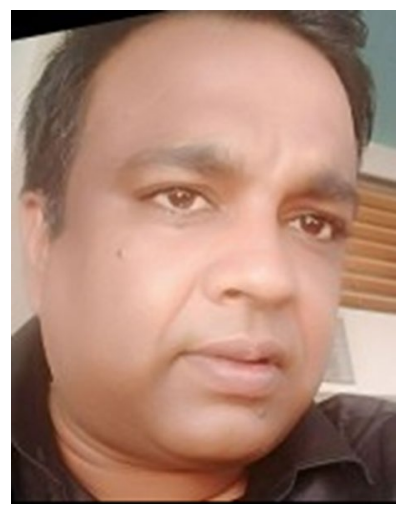

Vinaytosh Mishra is a Ph.D. (Supply Chain Management), IIT (BHU); MBA (Marketing and Operations), IMNUAhmedabad; PG Diploma (Statistics and Computing), ISCBHU; and B-Tech (ECE), IIT (BHU). He is working an Assistant Professor at FORE School of Management, New Delhi. Dr. Mishra has more than 13 years of experience in industries such as Healthcare, Manufacturing, Financial Services, Software, and IT. His research interest includes Healthcare management, Healthcare Supply Chain Management, Healthcare Informatics, and Digital Health.

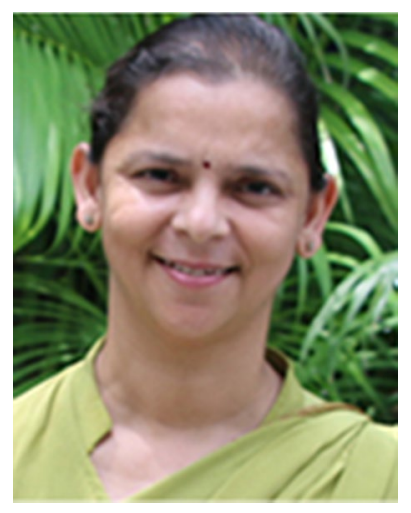

Mohita G. Sharma is a FPM, IIMLucknow; MPIB, IIFT; and B.Tech., IIT-BHU (Varanasi) Dr. Mohita Gangwar Sharma is a Professor at FORE School of Management. She has more than 23 years of experience in the Industry and Academics. She is the recipient of the coveted Chevening Rolls-Royce Science and Innovation Scholarship at SAID Business School, University of Oxford with experience both in manufacturing and service industries in managerial capacities in various operational roles. 